\title{
Community support shares risk
}

J. Agrar. Change https://doi.org/10.1111/joac.12280

(2018).

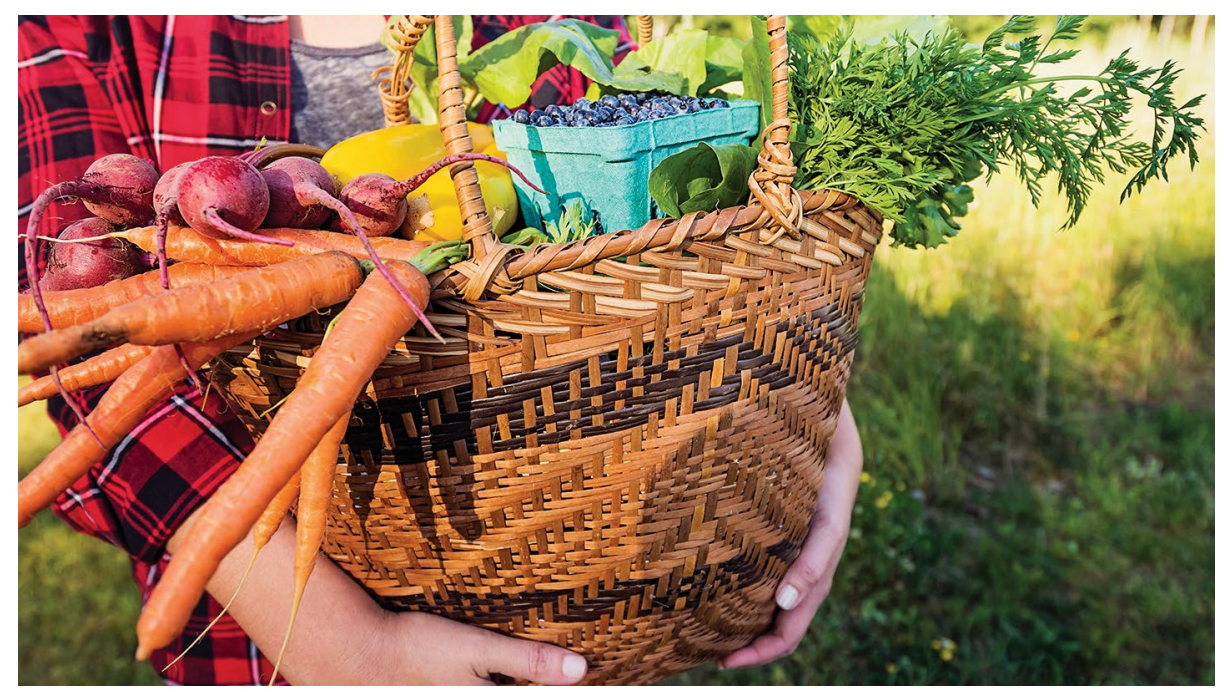

Credit: Daniel Grill/Getty

Despite modest subsidies from the United States government, small farmers struggle to make up an average income compared to the population at large, especially once interest payments on farm and working capital are paid out. Community-supported agriculture (CSA) was developed as an alternative form of capital for farmers, as well as providing consumers with fresh foods.

Mark Paul at Duke University, North Carolina, interviewed and examined the finances of 14 farms in Massachusetts that have CSA programs. Such programs typically allow consumers to sign up for a subscription of foods grown on the farm in exchange for a lump sum or monthly payment. Such payments then provide farmers with working capital throughout the year, rather than waiting until the harvest and/or taking out loans.

Mean net income for the farms in the sample was US\$12,000. While this is some $377 \%$ above the national average for on-thefarm income, it is still far below the average income for the population as a whole. However, farmers reported that CSA helps with the timing of income and disperses the operating risk in case of a bad harvest, as well as allowing them to diversify their crops and gain non-financial benefits through greater community involvement and providing healthy food to local residents.

\section{Ryan Scarrow}

Published online: 30 July 2018

https://doi.org/10.1038/s41477-018-0228-4 